\title{
Reportaje a Ánfora
}

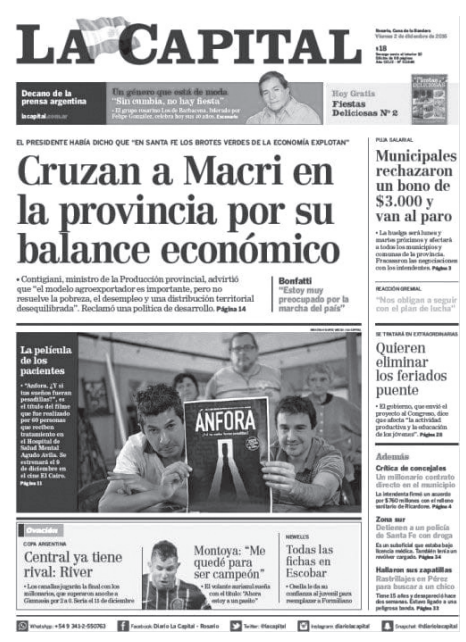

Participantes: Ignacio Blaconá (IB), Leo Villarruel (LV), y Entrevistadoras (E) Gisela Santanocito, Lorena Figueras.

E: Buenos días, ¿cómo les va, Ignacio, Leo? Los presentamos: Ignacio Blaconá, director de la película Ánfora. Leo Villarruel, protagonista. La película, que es una producción del centro cultural El Gomecito. ¿Qué significa/significó Ánfora para ustedes?

LV: Hola, mi nombre es Leo y soy el protagonista más siniestro de la película. Y bueno, para mí Ánfora... No me voy a referir a la realización de la película que fue como un trabajo, sino a cuando vi la película, voy a focalizar en ese momento. Para mí fue un hecho histórico, un sueño cumplido, equiparable a cuando me recibí de abogado. Estoy hablando de cuando yo me vi en la pantalla grande, en la película. Para mí significó eso: un hecho histórico, un sueño cumplido y se lo debo más que nada a Nacho -a Ignacio Blaconá- que fue el director de la película. Eso significó para mí Ánfora. Y además de trabajar con un montón de chicos en un muy buen grupo humano, significó fortalecer algunos vínculos. No solo sociales... Yo hacía mucho tiempo que ya no tenía vínculos más que en el barrio donde vivía. Y entonces, esa apertura fue como un despertar en esta película. Yo focalizo más que nada en el día en que me vi en la película que fue un despertar, fue un hecho histórico en mi vida. Equiparable, como digo, al momento en que me recibí de abogado.

IB: Con respecto a qué significa Ánfora, concretamente para mí, fue el proyecto más ambicioso que planteamos desde el Centro Cultural Gomecito (al menos en lo que a mí me compete: el taller de producciones audiovisuales) y que pudimos finalizar, que pudimos concluir de forma exitosa, porque nos encontramos con múltiples obstáculos en el camino. Lo planteamos como un largometraje de ficción, así que son muchísimas las complejidades que tiene, los obstáculos que nos fuimos encontrando en la preproducción y en el rodaje mismo. Así y todo, no claudicamos en nuestra idea original de hacer una película, ese sueño de algún día poder proyectar una película del centro cultural en un cine de la ciudad. Esto fue en el cine "El Cairo", con sala llena, con toda una expectativa, con toda una movilización de trabajadores, de vecinos y de gente de distintos palos artísticos de la ciudad, que también colaboró de alguna manera. Para mí es, como dije al principio, el proyecto más ambicioso que pudimos abordar y finalizar con éxito. Y como les decía, a pesar de todos esos obstáculos, no claudicar en la idea. Los obstáculos no fueron los de producción de un largometraje de ficción, sino de la dinámica de nuestro centro cultural y de los participantes de nuestros talleres. Por eso, nos encontramos con que era muy difícil a veces plantear escenas y plantear un guion que debíamos respetar. Más allá de las dificultades técnicas: nosotros no teníamos experiencia en una producción así, de semejante envergadura. Habíamos hecho documentales, hasta nos animamos a hacer un ciclo para televisión, pero nunca un largometraje. Es como el partido más difícil. Cualquier persona que se involucra de alguna manera en un largometraje documental o un largometraje de ficción... todo el tiempo, toda la energía que 
uno tiene que poner para que ese proyecto vea algún día la luz. Y bueno, eso también es lo que yo llevo como una alegría y un inmenso honor, el haber podido mantener desde un principio esas ganas, esa motivación de terminarla. Hoy por hoy podemos decir que orgullosamente el Centro Cultural Gomecito tiene una película en la que están involucrados tanto usuarios como trabajadores, con el mismo nivel de compromiso. O participaron cada uno en lo que podían y se comprometían a aportar desde su lugar. Así que llevo con orgullo, haber podido terminarla y hoy estar hablando de los resultados, de lo que dejó esta película.

E: ¿Cómo surge la iniciativa de filmar Ánfora?

LV: Surge a raíz de que Nacho, como director del taller audiovisual, junto con Tito Ramone, que es un usuario que participa del taller -los dos tienen un fanatismo por el cine, al grado tal de una locura, locura por el cine [ríe], los considero dos psicópatas del cine-y yo, que también formaba parte del taller, fui el tercer loco por el cine (tenía conocimientos sobre cine, me gustaba, pero no sabía nada sobre hacer cine). Y bueno, esta conjunción de nosotros tres... yo tomé el personaje que me eligieron como actor, para hacer este personaje siniestro de la película. Esta locura de los tres de hacer una película fue un sueño cumplido, desde mi parte. Así fue como se inició la experiencia de Ánfora, producto de estos dos psicópatas. Y me sumaron a mí como el tercer loco, para la parte de actuación, y logré compenetrarme y hacer lo que habíamos planeado para la película.

IB: Con respecto a cómo surge la iniciativa, es a partir de nuestros encuentros en el taller audiovisual. Allí nos encontramos gente a la que nos gusta ver películas. Sentimos pasión por el cine. Pero no solo nos gusta mirar películas, sino que también nos gusta realizar nuestros propios experimentos audiovisuales. Así fue que nos embarcamos en esto de construir un guion, desde cero, con ideas que tenían algunos de los usuarios. De ellos, algunos llegaron hasta el final y otros quedaron en el camino, pero muchos siguieron aportando (personajes, escenas), y así fuimos componiendo esta película, que surgió por eso: simplemente por el interés, las ganas y lo felices que nos hace estar produciendo un hecho audiovisual. Siempre lo hacemos con muchas ganas porque es algo que nos gusta. Nos gusta poder expresarnos, para nosotros las producciones audiovisuales son una herramienta fundamental y muy valiosa en la comunicación.

E: Escuchamos que han sorteado obstáculos, que no claudicaron en la idea de producir un largometraje: ¿Recuerdan alguna viñeta de la experiencia que quieran compartir? También mencionan que la película es o ha sido un acontecimiento, hecho histórico: ¿Qué condiciones institucionales, de trabajo en equipo, prácticas en salud mental se dieron o acompañaron el proceso de producción de la peli?

IB: Una de las grandes anécdotas es que salimos en la tapa del diario La Capital. No es poca cosa: la nota, una de las más significativas, ahí con la foto para el diario. A la mañana siguiente, después de que nos hicieran la nota en el Gomecito, me despierta un amigo y me dice "Nacho, estás en la tapa del diario La Capital con unos compañeros del Gomecito”. Nos habían venido a hacer una nota, pero jamás nos íbamos a imaginar que íbamos a estar en la tapa del diario. Así que fue un acontecimiento, realmente, con mayúscula, el estreno de la película. Y después en cuestiones laborales, con el equipo: una producción audiovisual es un trabajo en equipo -y por eso yo decía lo de los obstáculos-, acá era toda gente sin experiencia, nunca participamos en una producción tan compleja, por eso en todo momento nos encontrábamos con dificultades para trabajar. Por ejemplo, pacientes que tenían un rol, un personaje en la película, y les dieron 
de alta o terminó el tratamiento o por algún motivo no tuvieron más ganas de participar de la película o simplemente se alejaron. Entonces tuvimos que reemplazarlos por otros o modificar el guion o agregar una escena distinta o sacar otra, para ir sorteando esos obstáculos. Por eso digo que teníamos esos problemas. En una de las escenas, Leo termina haciendo otro papel más, sumado a su protagonismo en la película. Fue una situación que no estaba prevista y como no vino ese actor el día del rodaje de esa escena (que además era muy compleja porque había mucha gente) tuvimos que pensar en una alternativa y bueno, la alternativa fue que Leo reemplazara a ese otro personaje. Pero Leo ya tenía un papel, entonces tuvo que hacer dos papeles ese día. Era pensar siempre cosas sobre la marcha. Imprevistos. Eso también tiene que ver con una producción audiovisual. Otra cosa que nosotros veíamos mucho, trabajando con la improvisación, en algunas producciones audiovisuales del Gomecito (porque habíamos encontrado una forma de trabajo, con otros coordinadores de talleres) y en esta película fue adaptarse al guion que había, a la historia, entonces había que respetar esa historia. Y no era fácil con algunos pacientes, participantes, usuarios. Era difícil que siguieran la historia al pie de la letra. Entonces siempre se abrían nuevos frentes de acción en la película. Y hay cosas que nunca las sistematizamos. Siempre se dice que el humor en la psicosis es difícil de abordar y acá también otro tema fue la repetición de ciertas escenas, de ciertos diálogos que queríamos que estuvieran en la película y no sé qué sentido o qué resultado habrán tenido en ciertas personas que participaron. Por eso digo, nunca sistematizamos, porque este trabajo fue una experiencia de abordaje de una película con un guion, del Gomecito. Así que eso queda pendiente de algún análisis que puedan hacer algún día los psicólogos junto con los que participaron en la película.

LV: Bueno, en cuanto a las condiciones de grabación y todo lo que tiene que ver con el proceso de la película, nos encontramos con varias facetas: la faceta del caos, de muchas personas, de tratar de ordenar ese caos. Incluso porque nosotros al principio pensamos una idea de película de ciencia ficción, de extraterrestres, pero dijimos "Vamos a ponernos de acuerdo en lo que queremos" y de acuerdo con las personas que éramos, como bien dijo Nacho, dijimos "Loco, vamos a poner un objetivo". A los tres nos gusta el terror, entonces ahí ya empezamos a variar. No sé si a variar o a desvariar [ríe]. Bueno, por nuestra locura por el género de terror, terminamos haciendo una película de terror. En cuanto a las cuestiones económicas: es una película de muy bajo presupuesto, así que fue todo a pulmón. En un momento, la locura, la locura de Nacho, que yo digo que es un psicópata: quería maquillaje, quería vestuario... [ríe] Como no conseguimos, tuvimos que aportar cada uno su propio vestuario, su maquillaje. En cuanto a las funciones, le quiero recordar a Nacho que no solo hice dos papeles en la película (hice del personaje más siniestro de la película y también de padre de familia), sino que también hice una colaboración técnica como ayudante de iluminación. En un momento, a la vez que actor tuve que ser asistente, porque no teníamos tanta gente que colaborara. Todos querían actuar, pero nadie colaborar detrás de escena: tener una luz, tener el micrófono. Como era un grupo muy reducido, yo, Nacho (dirigiendo y con la cámara) y el otro psicópata del cine que es Tito Ramone tuvimos que multiplicarnos y hacer varios papeles. Y bueno, como viñeta, comparto lo de Nacho, la tapa de La Capital. Para mí también fue otro hecho histórico. Haber visto Ánfora y la primera vez en mi vida que salí en la tapa de un diario. Más a mí, que yo quiero ser del jet set, como dice Soda Stereo.

E: Resaltan la producción creativa, la improvisación. Dicen que encontraron formas de 
trabajo con compañeres y coordinadores de otros espacios. ¿Cómo plantean la modalidad de trabajo en el taller audiovisual? ¿Qué vínculos encuentran entre el arte y la salud mental?

LV: Bueno, en el proceso creativo de Ánfora, hubo las dos situaciones, tanto planificación como creatividad, producto de los tres descerebrados que somos [ríe] Nacho, Tito Ramone y yo. $\mathrm{Y}$ en cuanto a lo que nos llevó el proceso entre creación e improvisación terminamos con un final feliz en una película de terror. Es en lo que coincidimos. Hoy no sé si la haríamos con un final feliz. Pero bueno, la uno terminó con un final feliz. En cuanto al proceso de trabajo con otros talleristas, depende más que nada de la voluntad de cada uno, el tiempo de disponibilidad y utilizar muy bien el tiempo que tiene cada uno para participar en la película. Eso, tres descerebrados que somos Nacho, Tito Ramone y yo. Eso, en cuanto al equipo. En cuanto al arte y la salud mental, creo que son complemento. Puede ser, como yo digo, una terapia. Se nos ocurrió, de acuerdo con el programa que tenemos en televisión, hacer una carrera que se llame cineterapia. Y después creo que el artista hace una obra de arte (la película es una obra de arte) y que no está loco el artista porque haga una obra de arte. Creo que no tiene que ver con eso. Y que el loco, por tener un padecimiento mental, tampoco se puede ver privado de realizar una obra de arte. Incluso, en la película nadie se da cuenta de que son usuarios, de que están internados ni nada que se le parezca, sino que pueden pasar como personas comunes. Así que eso es lo que pienso. Y eso de que el loco no puede hacer una obra de arte ni ser un artista: no podemos juzgarlo ni prejuzgarlo, sino que depende del contexto que esté viviendo cada persona o cada grupo como para realizar una película. Depende de la situación que esté viviendo, en ese presente, ese grupo o persona.

IB: Una película te da posibilidades creativas infinitas. Por eso es todo un desafío enorme meterse a hacer una película. Yo a veces veo que fue arriesgado el tema de largarnos a hacer un largometraje. Porque en tantas posibilidades que uno tiene, en tantas posibilidades creativas, uno también puede perderse. Y perder el rumbo, como bien cuenta Leo. Iba a ser de ciencia ficción y después termina siendo de terror. El tema de la violencia que iba a haber en la película la terminamos resolviendo de una manera más sugestiva, si se quiere. Y tantas otras cosas que hemos ido modificando. También llevar un guion a lo que es realizarlo, ahí aparecen las complicaciones. Bueno, ya hablamos de las complicaciones. Pero fue para mí arriesgado porque nos metimos y no teníamos práctica para algo así, tan grande. Nosotros en el taller audiovisual tuvimos muchísimas experiencias y realizamos muchos experimentos de género: habíamos comenzado con sketch, en los inicios del taller; después nos volcamos a unos cortometrajes. Y después nos metimos a un ciclo de TV. O sea, una cosa nos iba llevando a la otra. Nos íbamos sintiendo cada vez más fortalecidos y nos íbamos metiendo en algo más grande. Incluso, el tema de la locura y el arte siempre nos interesó. Es más, tenemos dos ciclos, que fueron transmitidos por Canal 4 y TV Regional, que tratan un poco desde distintas visiones lo que es el arte y la locura. El primero se llama Luces calientes, al que invitamos artistas y gente de distintas profesiones de la ciudad de Rosario y hablamos un poco sobre locura y arte, si hay algún vínculo entre las dos. Y el segundo es Pastillas, que fue con usuarios y trabajadores de salud mental, y lo preguntábamos por separado: qué representaba el arte, qué representaba la locura. Siempre aparecen muchas conexiones, pero son misteriosas esas conexiones. Y yo no puedo develarlas acá, porque si no estaría cometiendo un... [ríe] No, no, no voy a develarlas porque lo más lindo es que sigan siendo misteriosas esas conexiones. Y la forma de trabajar, ya lo dije, nos gusta experimentar. 
Hemos pasado por muchos formatos, desde la improvisación hasta trabajar con un guion. Cada uno con sus resultados, con sus potencialidades, con sus pros y sus contras. La primera vez que nos aferrábamos con Ánfora a un guion -si bien después fue mutando-, lo difícil con ciertos participantes era que respetaran esa idea. Muchas veces se iba por las ramas. También se me viene a la cabeza eso: que fue un desafío muy arriesgado lo de Ánfora. O quizás lo sentí yo, desde mi responsabilidad, mi rol. Sentí que era un barco muy grande, que había que timonearlo todo el tiempo para que no se hundiera como el Titanic. Pero por suerte lo llevamos a buen puerto. Y ahí está la película.

E: Vimos la película, y el Titanic estuvo bien conducido. Teniendo en cuenta la experiencia Ánfora: ¿Qué es la desmanicomialización?

LV: La desmanicomialización para mí es cerrar los manicomios. Y es para mí increíble que sí se dio esa tarea de desmanicomializar y se dio a través de la película Ánfora. Y no solo a través de la película, sino a través del dispositivo en el Gomecito. Se da todos los días, a través de los talleres, de ese lado macabro que es el manicomio. Cuando Julieta, que es la directora del Gomecito y una de las protagonistas de la película, cerró la puerta que comunicaba el Gomecito con el manicomio, con el Agudo Ávila. Ese acto que pareció una estupidez, fue un pequeño gran acto de desmanicomialización en su momento. Hoy en 2020, diez años después de la Ley de Salud Mental... Cuando la vea a Julieta le voy a decir que, así como se cerró en su momento que se abra, también bajo el discurso de desmanicomialización. Que se abra nuevamente esa puerta para que se dé la comunicación entre el Agudo Ávila y el Gomecito. Y después, en cuanto a qué es para mí es la salud mental: La salud mental es la coherencia y el equilibrio emocional que una persona, individuo tiene a lo largo de su vida. Y que va variando según el momento, circunstancias y medio circundante.

IB: Con respecto a la desmanicomialización, personalmente, trato de que mi trabajo en el Centro Cultural Gomecito tenga que ver con eso. ¿En qué sentido lo digo? En el de que las producciones culturales y artísticas tengan que ver con eso, con poder cruzar esa frontera de prejuicios y que cualquiera de estas producciones pueda ser vista o disfrutada por cualquier persona, por cualquier receptor sin que medie el prejuicio de quién las hace. Para eso, las cosas que vamos haciendo... o al menos mi interés está ahí: es comprometernos con cierto estándar de calidad de esas producciones, que no tengan ese condicionamiento, y de esa forma saltar esa barrera que no nos permite comunicarnos. Bueno, el arte es una herramienta de expresión. En mi caso, yo la utilizo para eso, para abonar a la desmanicomialización, para a través del arte dialogar con los destinatarios de nuestros productos. Eso, por un lado. Por otro, con respecto a la salud mental, creo que es una utopía. Se habla de la salud mental, o de cierta insanía o de cierta salud. Y me parece que no existe eso, cada uno tiene lo suyo, sus rollos, sus mambos. La salud mental me parece que sería lo más parecido a poder vivir de una manera más respetuosa con respecto a las diferencias de cada uno. Creo que esa sería una manera saludable de vivir. En una sociedad en la que las diferencias a veces establecen prejuicios. Trabajar para disolver esos prejuicios es trabajar en pos de la salud mental y de la desmanicomialización.

E: Por último, ubicar que Ánfora de alguna manera ha sido un punto de llegada, producto de un proceso que tiene una historia de la que ustedes han dado cuenta. En función de esto, quisiéramos preguntarles si tienen pensado o están pensando en algún otro proyecto.

IB: Siempre andamos con un proyecto bajo el brazo. Al menos en materia audiovisual, nos 
cansamos pronto (al menos yo me canso pronto) de lo que hacemos y siempre queremos experimentar algo nuevo. Embarcarnos en un proyecto que nos estimule, que nos de ganas de ser parte, a los que formamos el equipo y desandar ese camino. Pero a veces trato de no atormentarlos demasiado porque... bueno, esto Leo lo debe tener claro. Cada comienzo de año en los talleres proponemos película o cortometraje o programa de televisión... Lo más concreto este año es que hagamos Cine Café, un ciclo de entrevistas a personas ligadas al cine y a la producción audiovisual, pero no descarto que esta pandemia nos derive hacia otras cosas. Cuando podamos volver, veremos qué hacemos concretamente. También tenemos ganas de hacer la continuación de Ánfora, pero sin final feliz. Así que la dejamos ahí picando para ver con qué volvemos al taller audiovisual. Bueno, les mando un abrazo a todos, espero que haya servido esto de algo y que sea una entrevista productiva para la revista Barquitos Pintados.

LV: En cuanto a los proyectos, estamos con Cine Café junto a Tito Ramone y Nacho. Es la continuación de un programa que salía por televisión (no sé si está saliendo Cine Café I en estos momentos), en el cual entrevistamos a referentes locales que tienen que ver con el cine o son del jet set local. Es un programa que tiene que ver solamente con el cine porque, como ya dije, somos unos locos o psicópatas por el cine. Y bueno, el programa consta de una entrevista a mi cargo, un cinetest a cargo de Tito Ramone y todo en la dirección y edición de Nacho. Pero tiene que ver con el cine y con referentes del medio local. Esos son los proyectos de hoy. Y también a largo plazo quedaría hacer una Ánfora II, en la cual yo voy a hacer un personaje más diabólico que el de la primera, seguramente. Pero no es para esta instancia, está ahí en el freezer. Bueno, estamos llegando al final, espero que les haya servido esta entrevista. Llegamos a un final feliz, como con la película Ánfora. Final feliz para esta entrevista, así que gracias totales.

En el siguiente link, podrán encontrar y disfrutar la película: https://www.youtube.com/ watch?v=7BtG64QUGfA 